\title{
Het Penitentiair Psychiatrische Centrum: een volwaardige psychiatrische kliniek in de gevangenis?
}

\author{
J. Wesselius*
}

\section{Inleiding}

Er bestaat al jaren discussie over de psychiatrische zorg in detentie. Verschillende commissies en adviesgroepen ${ }^{1}$ hebben zich afgevraagd of de psychiatrische zorg in detentie kwantitatief en kwalitatief voldoende was en hoe zij het beste vorm gegeven zou kunnen worden. Dit resulteerde in de voorbereidingen voor een wet waarin vernieuwingen in de forensische zorg $^{2}$ worden geregeld. Hierin is onder andere de vorming van een aantal Penitentiair Psychiatrische Centra's (PPC) opgenomen. De PPC's zijn bedoeld voor de opvang van gedetineerden met ernstige psychiatrische problemen, aan wie binnen de reguliere detentie onvoldoende zorg en begeleiding kan worden gegeven. Er is veel discussie of deze instellingen de gegeven adviezen en kritische punten voldoende ondervangen. De vijf PPC's zijn echter ondertussen een feit. Ze staan in Amsterdam, Den Haag, Maastricht, Vught en Zwolle. De PPC's zijn verschillend van grootte en verkeren in verschillende stadia van ontwikkeling. Soms werd een PPC vorm gegeven vanuit een bestaande zorgsetting, anderen moesten nieuw opstarten.

In het PPC Amsterdam werken ongeveer 250 medewerkers en het heeft straks 128 'bedden' beschikbaar. In het PPC Amsterdam is ook de enige landelijke crisisafdeling gevestigd. De daar opgevangen gedetineerden zijn op deze afde-

* Jessica Wesselius is psychiater NIFP en directeur Zorg en Behandeling PPC Amsterdam.

1 Zie: 'Terbeschikkingstelling:, vandaag over gisteren en morgen', Eindrapport van de tijdelijke parlementaire commissie TBS, (zgn. 'commissie Visser'): 2006 - 'De zorg aan gedetineerden met een ernstige psychische stoornis of verslaving', Advies RSJ: 2007 - 'Sterk van Geest', Beleidsdocument IGZ: 2007.

2 De wet bevindt zich momenteel in fase twee: het wetsvoorstel forensische zorg is ingediend bij Tweede Kamer. 
ling aangewezen omdat zij meestal een gevaar vormen voor zichzelf of anderen ten gevolge van hun psychiatrische stoornissen.

Het PPC Amsterdam bestaat nu bijna twee jaar. De landelijke crisisafdeling bestond al veel langer. Dat is de voormalige Forensische Observatie en Begeleidingsafdeling (FOBA). Deze afdeling werd in de jaren tachtig opgezet als tijdelijke opvang voor gedetineerden die door hun ernstige psychiatrische problematiek in de reguliere detentie niet meer te handhaven waren. Deze crisisopvang blijkt onmisbaar voor het gevangeniswezen en werd daarom opgenomen in het PPC Amsterdam.

Dhr. $L$ wordt aangemeld bij de crisisafdeling van het PPC Amsterdam vanwege agressie. Hij is nu twee weken gedetineerd en veroorzaakt voortdurend problemen. Hij luistert niet, scheldt en schreeuwt onverstaanbaar. De dag voor overplaatsing vernielt hij zijn celinventaris en gooit een televisie naar het hoofd van een bewaker.

Patiënt wordt bij ons binnengebracht in hand-en voetboeien. Je hoort hem diverse afdelingen verderop nog schreeuwen en tieren. Het is een kleine, zeer magere man met een verwarde haarbos. Hij is vies en stinkt. In een gesprek met de psychiater kan hij geen volledige zin formuleren. Hij roept over God, complotten, hel en verdoemis. Afspraken maken over zijn gedrag kan hij niet en hij verzet zich voortdurend tegen de begeleiders. Dhr. L wordt in een isoleercel geplaatst.

\section{De ontwikkeling van de PPC's}

Project vernieuwing forensische zorg

In 2006 werden in het kader van een project vernieuwing forensische zorg voorbereidingen getroffen voor het ontwikkelen van de vijf PPC's. Het uitgangspunt is dat psychiatrische zorg en behandeling van justitiabelen plaats moet vinden in de geestelijke gezondheidszorg (GGZ), tenzij dat door het Openbaar Ministerie (OM) of de Minister niet wenselijk wordt geacht. In dat geval moet die zorg en behandeling plaats vinden binnen het gevangeniswezen. De geboden psychiatrische zorg moet equivalent zijn aan de zorg in de GGZ, waar- 
bij rekening wordt gehouden met de detentieomgeving. Dit resulteerde in juli 2007 in een concept zorgvisie. ${ }^{3}$

Deze visie loste een aantal belangrijke vragen vanuit het werkveld niet op. Wat is precies 'equivalentie van zorg'? Welke vormen van psychiatrische zorg moeten de PPC's bieden? Zijn de financiële middelen die de dienst justitiële inrichtingen (DJI) daarvoor ter beschikking stelt voldoende? Daarom werd in het najaar van 2009 door de PPC's aan de directie gevangeniswezen van DJI gevraagd de opdracht aan de PPC's te specificeren. Het concept 'kaderdocument zorg' ${ }^{4}$ was het antwoord. In dit document wordt gesteld dat het niet realistisch is te spreken over 'equivalente zorg' omdat de PPC's aan het begin staan van hun ontwikkeling. Vooralsnog moet er gesproken worden over 'verantwoorde zorg'.

\section{Opdracht aan de $P P C$ 's}

Het concept 'kaderdocument zorg'stelt: 'DJI draagt zorg voor verantwoorde medisch noodzakelijke zorg, die bij voorkeur moet plaatsvinden in de GGZ. Indien dit niet mogelijk is, volgt opname in een Penitentiair Psychiatrisch Centrum (PPC)' De PPC's moeten 'verantwoorde zorg leveren binnen detentie en binnen de beschikbare financiële kaders'. Ook dienen de PPC's 'een bijdrage te leveren aan het verminderen van het recidiverisico en zorg te dragen voor continuïteit van zorg door een nauwe samenwerking met de ketenpartners'. De PPC's zullen de geplaatste gedetineerden: 'stabiliseren, diagnosticeren, motiveren en mobiliseren, door- en terugplaatsen, beveiligen en voorzien in medisch noodzakelijke zorg en behandeling'.

Dit alles gebeurt binnen de context van de Kwaliteitswet Zorginstellingen, de Wet op de Geneeskundige Behandelovereenkomst (WGBO), de Wet Beroepen in de Individuele Gezondheidszorg (wet BIG), de Kwaliteitswet Zorginstellingen en de Penitentiaire Beginselenwet.

Enkele dagen na binnenkomst is dhr. Leen stuk rustiger. Hij reageert echter nog steeds op elke vorm van contact met schelden en hij maait wild met zijn armen om zich heen wanneer zijn begeleiders hem naderen. Hij is onder dwang gedoucht en bleek daarbij nog magerder dan eerder geschat werd. De psychiater

3 Bijzondere Zorg in Detentie, zorgvisie, Ministerie van Justitie, DJI:2007 in concept.

4 'Kaderdocument Forensische Zorg aan Gedetineerden: De Toekomst is nooit af: de Evolutie van een PPC', directie gevangeniswezen: 2010 in concept. 
consulteert de inrichtingarts en beiden maken zich ernstige zorgen over de voedingstoestand van patiënt. De psychiater overweegt om de directeur van het $P P C$ te adviseren om patiënt onder dwang een antipsychotisch middel toe te dienen in een spuit.

\section{Juridische en ethische kaders}

De psychiatrische zorg die in de PPC's geboden dient te worden, wordt niet alleen bepaald door de opdracht van het ministerie van Justitie. Er gelden voor de PPC's immers ook de internationale en nationale wetten en de beroepsnormen van de individuele zorgverleners.

De Europese Commissie ${ }^{5}$ is duidelijk over zorg in detentie.

'Health care

40.3 Prisoners shall have access to the health services available in the country without discrimination on the grounds of their legal situation.

40.4 Medical services in prison shall seek to detect and treat physical or mental illnesses or defects from which prisoners may suffer.

40.5 All necessary medical, surgical and psychiatric services including those available in the community shall be provided to the prisoner for that purpose.'

In ons eigen land heeft de Raad voor Strafrechttoepassing en Jeugdbescherming (RSJ) zich op soortgelijke wijze uitgelaten over de kwaliteit waaraan psychiatrische zorg in detentie moet voldoen'. Zij geven het advies om 'de zorg aan gedetineerden met een ernstige psychische stoornis of een verslaving op een niveau te brengen dat gelijkwaardig is aan de zorg in de samenleving (aanbeveling I, par. 5)' en om 'maatregelen te treffen waardoor gedetineerden uit deze doelgroep, aan wie deze zorg in detentie niet kan worden geboden, soepeler kunnen worden overgeplaatst naar de GGZ (aanbeveling I, par. 6).' Verder beschrijft de RSJ een aantal uitgangspunten voor de zorg aan gedetineerden met een psychische stoornis, waaronder het volgende: 'Uitgangspunt voor de zorg aan gedetineerden is dat deze gelijkwaardig dient te zijn aan de zorg in de vrije samenleving.'

5 'Recommandation Rec (2006) 2', Counsel of Europe, European Prison Rules: 2006.

6 'De zorg aan gedetineerden met een ernstige psychische stoornis of verslaving', Advies RSJ: 2007. 
Kortom: de individuele behandelaar in het PPC moet zich niet alleen houden aan de door justitie gegeven opdracht, maar uitdrukkelijk ook aan internationaal geldende wetgeving en beroepsnormen betreffende psychiatrische zorg. Dit levert een interessant spanningveld op en veel discussies tussen 'het veld' (de inhoudelijk zorgprofessionals die verantwoordelijk zijn voor het bieden van psychiatrische zorg aan hun patiënten) en 'het hoofdkantoor' (de directie gevangeniswezen die rekening moet houden met de politieke en financiële kaders). Die discussie gaat onverminderd voort. Niet alleen over de financiële kaders, maar ook over de organisatiestructuur (wie is waarvoor verantwoordelijk binnen welke hiërarchische structuur) en de formatie (welke en hoeveel professionals zijn nodig in een PPC). Dit gebeurt onder het toeziend oog van de Inspectie voor de Gezondheidszorg, een organisaties die zich voorheen binnen DJI afzijdig hield.

\section{De patiënten}

\section{Indicatiestelling}

De patiënten in een PPC komen uit de penitentiaire instellingen (PI) en bij uitzondering (in het geval van de crisisafdeling) de politiecellen. De indicatie voor een PPC wordt gesteld in het psychomedisch overleg (PMO) ${ }^{7}$ in de PI. In het uitzonderingsgeval van directe plaatsing vanuit een politiecel wordt de indicatie gesteld door een psychiater van de crisisdienst van de GGZ. Zij bepalen dat er 'klinisch psychiatrische zorg' nodig is. De onafhankelijke toetsing van de indicatiestelling voor een PPC vindt achteraf plaats door het bureau Indicatiestelling Forensische Zorg (IFZ). Dit is een onderdeel van het Nederlandse Instituut voor Forensische Psychiatrie en Psychologie (NIFP) ${ }^{8}$. Voor plaatsing in een PPC geldt zoals' gezegd, het principe 'GGZ tenzij': gedetineerden met een psychiatrische zorgbehoefte worden naar de GGZ geleid, tenzij dat niet mogelijk is. Wanneer een patiënt toch geplaatst wordt in het PPC betekent dit dat hij weigert mee te werken of dat het OM, of het Bureau Selectie-

7 Het PMO is een regulier overleg in de P.I. en bestaat in ieder geval uit een psychiater van het NIFP, een GZ-psycholoog, een inrichtingsarts en een penitentiair verpleegkundige.

8 www.nifpnet.nl. 
functionaris (uit naam van de minister van Justitie) doorgeleiding naar de GGZ niet goedkeurt.

\section{Patiënten kenmerken}

De patiënten die instromen in de PPC's vormen een zeer heterogene groep, waarvan de inclusie criteria 'gedetineerd' en 'psychiatrische zorgbehoefte' zijn. De indicatie voor verwijzing kan een psychiatrische stoornis, een persoonlijkheidsstoornis, verslaving of zwakbegaafdheid zijn. In de praktijk gaat het bij de meerderheid van de PPC populatie om patiënten met een combinatie van deze stoornissen. Daarnaast heeft de meerderheid van de patiënten gedragsproblemen en forse psychosociale problematiek.

De diagnostiek en sociale situatie van $L$ worden steeds duidelijker. Hij is een schizofrene en verslaafde man van Antilliaanse afkomst. Hij leeft al een jaar of tien op straat. Daar valt hij mensen lastig, met name toeristen, die hem als bedreigend en agressief ervaren. In de drugsscène is hij niet bestand tegen de andere verslaafden en wordt zijn gebedelde geld hem vaak weer afgepakt. Hij is bekend bij de psychiatrische hulpverleners. Zij geven aan dat zij niets met hem kunnen als hij drugs gebruikt: dan is hij agressief en wil niet meewerken. Familie is uit beeld. Vrienden en kennissen zijn er niet. Patiënt heeft geen inkomen en geen huisvesting.

\section{Juridische titels}

Ook de justitiële titels van de patiënten zijn divers. De meerderheid van de gedetineerden in Nederland is kort of preventief gehecht (meer dan 80\%). Dit lijkt ook voor de PPC populatie te gelden. Binnen het PPC Amsterdam is momenteel iets minder dan de helft van de patiënten preventief gehecht. Slechts een klein percentage van de PPC populatie is langdurig gestraft. Daarnaast verblijven er een gering aantal (ongewenste) vreemdelingen en TBS- en art. 37 passanten in de PPC's.

\section{Rechtspositie}

Plaatsing in een PPC gebeurt niet altijd op vrijwillige basis. Wanneer dat het geval is, kan een in het PPC opgenomen patiënt bezwaar aantekenen tegen zijn plaatsing. Dit bezwaar moet hij in eerste aanleg maken bij de functionaris die 
hem plaatst en dat is de medewerker van het Bureau Selectiefunctionaris. Pas in een later stadium kan hij bezwaar bij de RSJ aantekenen. Daarmee is de plaatsing in een PPC op onvrijwillige basis wezenlijk anders geregeld dan de onvrijwillige opname in de GGZ.

Een gedetineerde in een PPC heeft dezelfde rechtspositie als alle gedetineerden en valt onder de Penitentiaire Beginselenwet.

\section{Verblijfsduur}

Naar de gemiddelde verblijfsduur van patiënten in de PPC's is nog geen onderzoek gedaan. In het PPC Amsterdam is de gemiddelde verblijfduur op de reguliere afdeling momenteel ongeveer vier maanden. Over de crisisafdeling zijn er meer gegevens voorhanden. De gemiddelde verblijfsduur is daar elf tot dertien weken. Deze afdeling heeft een hoge doorstroom: er zijn 300 tot 350 opnames per jaar op 66 bedden.

De duur van het verblijf van een patiënt op een PPC wordt meer bepaald door de justitiële titel dan door de psychiatrische zorgbehoefte. Patiënten worden vrijgelaten, geschorst of uitgezet gebaseerd op het verloop van hun rechtsgang. Deze verloopt onafhankelijk van de aanwezige psychiatrische problematiek. De justitiële titel bepaalt of iemand doorgeplaatst kan worden naar een Forensisch Psychiatrisch Centrum (met de maatregel TBS) of naar een GGZ instelling (in het kader van een maatregel artikel $37 \mathrm{Sr}$ ). Op dit soort overplaatsingen heeft het PPC geen invloed.

\section{Nazorg}

Naar de uitstroom van de patiënten van een PPC is nog geen onderzoek gedaan. Het PPC Amsterdam verwijst momenteel ongeveer een derde van zijn patiënten door naar een psychiatrische instelling buiten detentie. Helaas is er een klein aantal patiënten, zoals ongewenst vreemdelingen, waarvoor niets kan worden geregeld. Zij verlaten detentie zonder nazorg. 


\section{Het behandelaanbod van de PPC's}

\section{Stabiliseren}

Bij stabilisatie op de crisisafdeling gaat het vooral om het voorkomen van schade aan de patiënt zelf of aan anderen. Deze groep patiënten heeft zeer intensieve begeleiding nodig. Agressie en andere gedragsstoornissen zijn regel. Het beveiligingsniveau ligt daarom hoger dan binnen reguliere detentie en de mate van begeleiding op individueel nivo is zeer hoog.

Stabilisatie op de reguliere PPC afdelingen heeft een minder heftig karakter. Er is meer ruimte voor het aanleren van alternatief gedrag bij de patiënt en therapeutische interventies. Er is ook meer ruimte voor psycho-educatie en het bespreken van het ziekteproces en de diagnose met de patiënt. Het beveiligingsniveau is conform de gangbare norm binnen detentie.

\section{Diagnostiek}

Voor een gedegen diagnostisch onderzoek is het van belang dat er voldoende geschoolde professionals beschikbaar zijn, die kennis hebben van de forensische psychiatrie. Ook moeten er voldoende tijd en middelen voorhanden zijn, zoals testmateriaal en de mogelijkheid om de patiënt frequent en langdurig te zien. Er is meestal niet veel informatie voorhanden en een goede hetero anamnese en een betrouwbare biografie ontbreken vaak. De patiënten op een PPC hebben bovendien vaak meerdere stoornissen en problemen die het beeld verder compliceren.

Omdat dhr. L op een laag cognitief intelligentieniveau lijkt te functioneren, wordt er bij hem een neuropsychologisch onderzoek afgenomen. Hij blijkt inderdaad op een 'beneden gemiddeld intelligentie nivo' uit te komen. Onduidelijk is of hij zwakbegaafd is geboren of dat hij cognitieve schade opgelopen heeft door zijn schizofrenie. Een heteroanamnese en biografie zijn immers niet mogelijk.

\section{Motiveren en mobiliseren}

De meeste patiënten op het PPC zijn daar niet vrijwillig geplaatst. De medewerking aan behandeling is vaak laag en patiënten hebben weinig ziektebesef en -inzicht. Motiveren voor behandeling en begeleiding vindt plaats in de vorm van psycho-educatie en regelmatig contact met hulpverleners. Daarnaast worden 
zinvolle dagactiviteiten aangeboden om zo de patiënten in beweging te krijgen. Verder is er plaats voor het aanleren van bepaalde basisvaardigheden op het gebied van levensstijl, verslavingsgedrag, arbeid en/of daginvulling.

Een week of drie later is dhr. L sterk veranderd. Veel met hem praten heeft ervoor gezorgd dat hij vrijwillig medicatie is gaan innemen. Hij is gaandeweg de begeleiders gaan vertrouwen en hij douchet nu zelf. Ook eet en drinkt hij weer. Hij verblijft op een reguliere afdeling van het PPC en dat gaat redelijk. Wel is duidelijk dat hij zeer veel behoefte heeft aan 'rust, reinheid en regelmaat': veel structuur en niet te veel spanningen.

Door- en terugplaatsen

Zoals gezegd verblijft het grootste deel van de patiënten kort op een PPC. Snelle stabilisatie is daarom noodzakelijk, in de hoop om de patiënten 'klaar te stomen' voor een nazorgtraject binnen of buiten detentie. Het is essentieel dat er vanaf de eerste dag ingezet wordt op nazorg. Doorverwijzing gebeurt niet alleen op grond van de overweging wat er nodig is aan psychiatrische zorg maar ook op wat haalbaar is. Door de vaak korte verblijfsduur of bij een (onverwachte) onmiddellijke invrijheidsstelling kan het gebeuren dat iemand doorverwezen wordt naar een setting die minder geschikt is, omdat er op korte termijn niets beters te regelen is.

Ons nazorgteam gaat hard aan de slag met meneer $L$, zeker nu duidelijk wordt dat hij over een aantal weken in vrijheid wordt gesteld. Hij zit voor een minder ernstig delict vast. Inmiddels zijn we een week of vier verder en veel langer dan twee maanden zal hij waarschijnlijk niet hoeven te blijven. Vanwege de uitgebreide psychosociale problematiek en het feit dat patiënt als hij drugs gebruikt niet meer bereikbaar is voor hulpverlening, wordt een rechterlijke machtiging in het kader van de wet Bijzondere Opnemingen in Psychiatrische Ziekenhuizen (BOPZ) aangevraagd. De machtiging wordt afgegeven. Patiënt vertrekt de dag van invrijheidsstelling naar een psychiatrische kliniek. Hij is vastbesloten geen drugs meer te gebruiken en belooft mee te werken aan een psychiatrische behandeling. Hij neemt afscheid van de begeleiders, aan wie hij inmiddels erg gehecht is geraakt. 


\section{Ketenvorming ten behoeve van. continuïteit van zorg}

Eén van de speerpunten in de concept wet vernieuwing forensische zorg is nazorg en continuïteit van zorg. De meervoudige psychiatrische- en gedragsproblemen van de patiënten maakt de uitstroom naar de GGZ niet gemakkelijk. Er zijn weinig geschikte zorginstellingen voor deze patiënten. Om hen toch te kunnen resocialiseren is het essentieel dat er een goed samenwerkingsverband ontstaat met alle betrokken ketenpartners buiten detentie. Dit betreft partners zoals de GGZ, verslavingszorg, licht verstandelijke gehandicapten (LVG) zorg, de Gemeentelijke Gezondheidszorgdiensten (GGD), daklozenopvang, gemeentes en uitkeringsinstanties.

Het PPC Amsterdam heeft een redelijke infrastructuur opgebouwd en neemt deel aan structurele overleggen met de locale GGZ partners, de gemeente en regionale Forensisch Psychiatrische Klinieken (FPK) en Forensisch Psychiatrische Afdelingen (FPA) van GGZ organisaties. Ook vindt er regelmatig overleg plaats met de afdeling IFZ van het NIFP Amsterdam, die een rol speelt in doorplaatsing.

\section{Recidivevermindering}

Omdat de meerderheid van de patiënten in het PPC kort of preventief is gehecht, kunnen nauwelijks interventies aangeboden worden die zich direct op het delict en recidivevermindering richten. Hierbij kan gedacht worden aan het bepreken van een delictscenario. Preventief gehechten zijn nog niet veroordeeld en kort gehechten zijn niet lang genoeg gedetineerd om dit soort intensieve zorgprogramma's te doorlopen.

Recidivevermindering betekent bij deze groep dan ook veel meer al in een vroeg stadium van de detentie werken aan continuïteit van zorg met aandacht voor alle levensgebieden (onder andere. huisvesting, financiën, legitimatie, dagbesteding). Hierbij kan beredeneerd worden dat stabilisatie van psychiatrische problematiek en inbedding in een nazorgtraject probleemgedrag zal verminderen en daarmee kans op delicten verkleint. Hoewel dit beperkt is onderzocht, zijn er wel aanwijzingen dat deze redenering klopt. ${ }^{9}$

9 Henry J. Seadman E.A., 'Effect of mental health courts on arrests and jail days', Archives of general psychiatry: 2010. 


\section{Slotbeschouwing en conclusies}

Hectiek kenmerkt in grote mate het werk in de PPC's. Het juridische kader, de ernst van de psychopathologie en de enorme heterogeniteit van de patiëntengroep bepalen de (on)mogelijkheden van het behandelaanbod aan de patiënten. Hierbij worden de duur en intensiviteit van de zorg vooral bepaald door de justitiële titel. De patiënt komt meestal snel vrij waardoor de doelstellingen voor opname op het PPC eveneens snel gerealiseerd moeten worden. De werkdruk is daarom hoog.

Hoe de PPC's zich uiteindelijk verder ontwikkelen zal de toekomst uitwijzen. Worden de PPC's uiteindelijk opgeheven, omdat ze hun werk zo goed doen dat alle psychiatrische patiënten in detentie snel naar de reguliere GGZ worden verwezen? Zal een nieuwe wet forensische zorg dit ondersteunen wanneer deze wet de mogelijkheden biedt om gedetineerden gemakkelijker buiten detentie te behandelen? Dit is mogelijk. Het is echter meer waarschijnlijk dat een groep gedetineerden overblijft die niet naar de GGZ wil of kan, omdat zij een te hoog beveiligingsniveau behoeven en/of er geen goedkeuring vanuit het $\mathrm{OM}$ of de Minister komt.

Is de GGZ in staat deze groep forensische patiënten op te vangen en te behandelen? Gedeeltelijk is dit zo. Er zijn wel aanpassingen binnen de GGZ nodig, om het hen mogelijk maken om te gaan met een groep psychiatrische patiënten met verschillende problemen zoals verslaving, verstandelijke handicap en/of gedragsproblemen. Het is een groep patiënten waarvan een aanzienlijk percentage blijvende structuur en veiligheid nodig zal hebben in een beschermde en beschermende omgeving, gedurende maanden tot jaren. Dit soort voorzieningen zijn momenteel in de GGZ en de verslavings- of verstandelijk gehandicaptenzorg niet overal voorhanden.

De asielfunctie van de GGZ is in de jaren tachtig terecht teruggebracht, maar de maatschappij is daarin doorgeslagen. Er is nu tijd om een gedeeltelijke beweging terug te maken en resocialisatie- en verblijfsafdelingen voor deze groep psychiatrische patiënten in te richten. ${ }^{10}$

10 J.C. Zwemstra, Psychiatrische zorg in en aansluitend aan detentie. Een onderzoek naar psychiatrische zorg en behandeling in detentie en daarop aansluitende reguliere of forensische zorg (diss. UvT), Nijmegen: WLP 2009. 
Dat brengt mij op de noodzaak van iets, waar nu nog weinig aandacht voor is: gestructureerd wetenschappelijk onderzoek naar de resultaten van het werk van de PPC's. Dit moet het liefst snel opgezet worden. Wat werkt wel en wat werkt niet? Worden onze patiënten beter van een verblijf in de PPC's en zijn ze dan sociaal beter ingebed? Wat is het effect van goede nazorg? Heeft dit een positief effect op de recidivecijfers van delicten? En zo ja, van welke delicten?

Als we over een aantal jaren het effect van de PPC's willen beoordelen én gefundeerd iets willen zeggen over de waarde van deze instellingen dan hebben we deze informatie nodig. Er is een schat aan gegevens voorhanden in de PPC's over deze groep forensisch psychiatrische patiënten. We kunnen de PPC's niet op hun waarde schatten wanneer we deze informatie niet structureel verzamelen, bekijken en evalueren.

Acht weken later wordt dhr. L weer bij ons aangemeld. Hij is dan sinds een week of twee opnieuw gedetineerd. Een dag na opname in de psychiatrische kliniek is hij ontsnapt, heeft op straat flink drugs gebruikt, stopte zijn medicatie en is psychotisch geraakt. Bij ons komt patiënt opnieuw vermagerd en vervuild, maar dit keer met een stralende glimlach de afdeling op. Hij begroet alle begeleiders hartelijk. Hij is verward maar zeker niet agressief en dit keer hebben we hem binnen een week of twee weer in het gareel.

Als ik met hem probeer te spreken over wat er buiten is gebeurd kijkt hij me met grote, nietszeggende ogen aan. Maar als het gesprek bijna over is en hij met de deurknop in zijn hand staat om weg te gaan, draait hij zich om. 'Weet $u$ wat het is dokter. Die wereld daarbuiten, die is gewoon te groot voor mij.' En eigenlijk, vertrouwt hij me toe, is hij blij dat hij weer bij ons terug is. 